\title{
Anterior Interosseous Nerve Palsy Following Proximal Humeral Fracture: A Case Report
}

\author{
Amir Sobhani Eraghi ${ }^{1}$ (D), Nima Hosseinzadeh ${ }^{2 * i[}$ \\ 1. Dept. of Orthopedics Surgery, Rasoul Akram Hospital, Iran University of Medical Sciences, Tehran, Iran \\ 2. Bone and Joint Reconstruction Research Center, Shafa Orthopedic Hospital, Iran University of Medical Sciences, Tehran, Iran
}

\begin{tabular}{|c|c|}
\hline Article Info & ABSTRACT \\
\hline doi $10.30699 / j a m b s .28 .126 .17$ & \multirow{3}{*}{$\begin{array}{l}\text { Anterior interosseous nerve (AIN) palsy after proximal humeral fracture is very rare } \\
\text { syndrome. This report presents a } 21 \text {-year-old man with axillary nerve and AIN palsy } \\
\text { following a proximal humeral fracture. The fracture was treated with open reduction } \\
\text { and internal fixation, and nerve palsy was treated conservatively. At 6-month follow- } \\
\text { up, proximal humeral and distal radius fractures had a complete union. There was no } \\
\text { subluxation of the humeral head, due to complete deltoid muscle recovery. Range of } \\
\text { motion of the shoulders was complete and symmetric. FPL, index FDP and deltoid } \\
\text { muscles had full strength. EMG revealed complete recovery of the axillary nerve and } \\
\text { AIN injury. }\end{array}$} \\
\hline $\begin{array}{l}\text { Received: 2019/10/07; } \\
\text { Accepted: 2019/12/28; } \\
\text { Published Online: 01 Jan 2020; }\end{array}$ & \\
\hline $\begin{array}{l}\text { Use your device to scan and read the } \\
\text { article online }\end{array}$ & \\
\hline \multirow{2}{*}{ 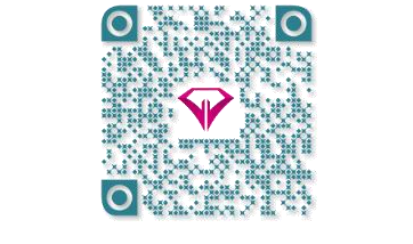 } & $\begin{array}{l}\text { Keywords: Anterior interosseous nerve palsy, Axillary nerve injury, Neuropraxia, } \\
\text { Proximal humeral fracture }\end{array}$ \\
\hline & $\begin{array}{l}\text { Corresponding Information: } \\
\text { Nima Hosseinzadeh, Bone and Joint Reconstruction Research Center, Shafa Orthopedic Hospital, Iran } \\
\text { University of Medical Sciences, Tehran, Iran } \\
\text { E-mail: hosseinzade.nima@gmail.com }\end{array}$ \\
\hline (c) $\underset{\mathrm{BY}}{(\mathrm{HC}}$ & $\begin{array}{l}\text { iccess article distributed under the terms of the Creative Commons Attribution-noncommercial } 4.0 \text { International License which permits } \\
\text { n noncommercial usages with proper citation. }\end{array}$ \\
\hline
\end{tabular}

\section{Introduction}

Proximal humeral fractures are the most common type of fracture affecting the shoulder girdle in adults, accounting for almost $7 \%$ of all such fractures (1). Although neurological injury after proximal humerus fracture is not common, displaced fractures due to high energy trauma (especially those with medial displacement of the humeral shaft segment and concurrent arterial injury) are associated with a high risk for nerve injury (2). The most frequently affected nerves are the axillary nerve $(58 \%)$ and suprascapular nerve (48\%) (3). To the best of our knowledge, there is only one report of isolated anterior interosseous nerve (AIN) palsy caused by a proximal humeral fracture (4). The current report presents a patient with axillary nerve and AIN injury following a proximal humeral fracture.

\section{Case Report}

A 21-year-old man was admitted to the emergency department following an injury to his left upper extremity due to a car accident. After clinical evaluation of the patient and after the absence of injuries to other parts of the body were confirmed, we found tenderness, ecchymosis, swelling, and limited motion of his left shoulder and wrist due to pain. Radiographs showed a severely displaced left proximal humeral fracture with comminution and a minimally displaced left distal radius fracture (Figure 1). A comprehensive neurological examination revealed hypoesthesia on the skin overlying the lateral aspect of the proximal arm. A motor examination of the deltoid muscle was difficult to perform due to pain but decreased deltoid muscle tone in comparison to the other side, and surprisingly, the patient was unable to make the "OK" sign (Figure 2). The flexor pollicis longus (FPL) and index flexor digitorum profundus (FDP) had no power. Because of wrist pain, pronator quadratus muscle testing was impossible. There was no wound, tenderness, or fracture around the elbow joint and upper forearm that would suggest traumatic nerve injury. Neurological examinations of the musculocutaneous, radial, ulnar, and median nerve (except for the AIN branch) were normal. There was no sign of vascular injury, either. The findings were consistent with a left axillary nerve injury and isolated AIN palsy. Because of severe fracture displacement and the possibility of further injury to the neurovascular system, closed reduction was done at the emergency department, but the reduction was not satisfactory for conservative treatment. Therefore, by considering the ipsilateral distal radius fracture, the unsatisfactory reduction, and the patient's age, open reduction and internal fixation (ORIF) was done via a 
deltopectoral approach with a 3.5-mm locking proximal humerus plate. Closed reduction and percutaneous pinning were also performed for distal radius fracture because of dorsal tilting.

After a three-week follow-up, there was mild deltoid atrophy in the left shoulder and little improvement in recovery of AIN (Figure 3). Initial Electromyography (EMG) and Nerve Conduction Velocity (NCV) tests demonstrated axillary and AIN injury. Passive range of motion started 4 weeks after surgery with forward elevation, external rotation and pendulum exercises.

After a six-week follow-up, the strength score of both FPL and index FDP was about 3 to 4 from 5 . Deltoid examination was difficult to perform due to long-term immobilization of proximal humeral fracture, but its force had slightly improved. Because of the spontaneous gradual recovery, surgical intervention seemed to be unnecessary. Both proximal humerus and distal radius fractures had adequate healing in radiographs; therefore, pins were removed and active-assisted range of motion was started.

At a 3-month follow-up, examination revealed an almost complete resolution of AIN and axillary nerve injury.

At 6-month follow-up, proximal humeral and distal radius fractures had a complete union. There was no subluxation of the humeral head, due to complete deltoid muscle recovery (Figure 5). Range of motion of the shoulders was complete and symmetric (Figure 4). FPL, index FDP and deltoid muscles had full strength. EMG revealed complete recovery of the axillary nerve and AIN injury.
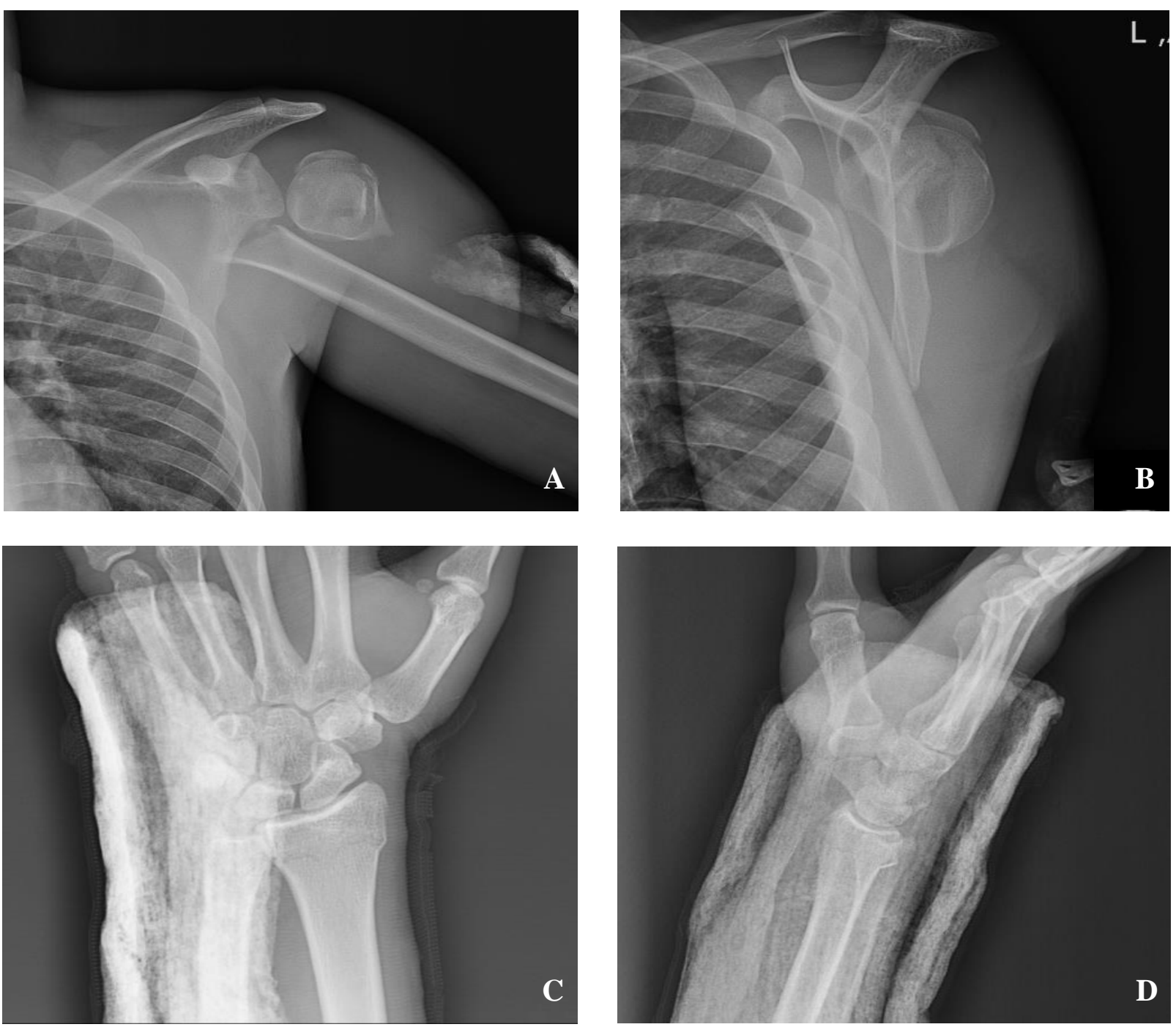

Figure 1. Radiographs showing left proximal humeral (A, B) and distal radius fractures (C, D) 


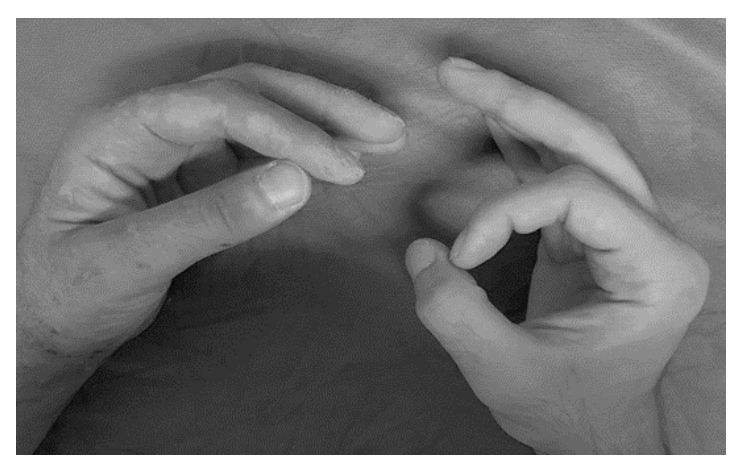

Figure 2. Photograph of the patient showing inability to flex distal phalanges of his left thumb and index finger
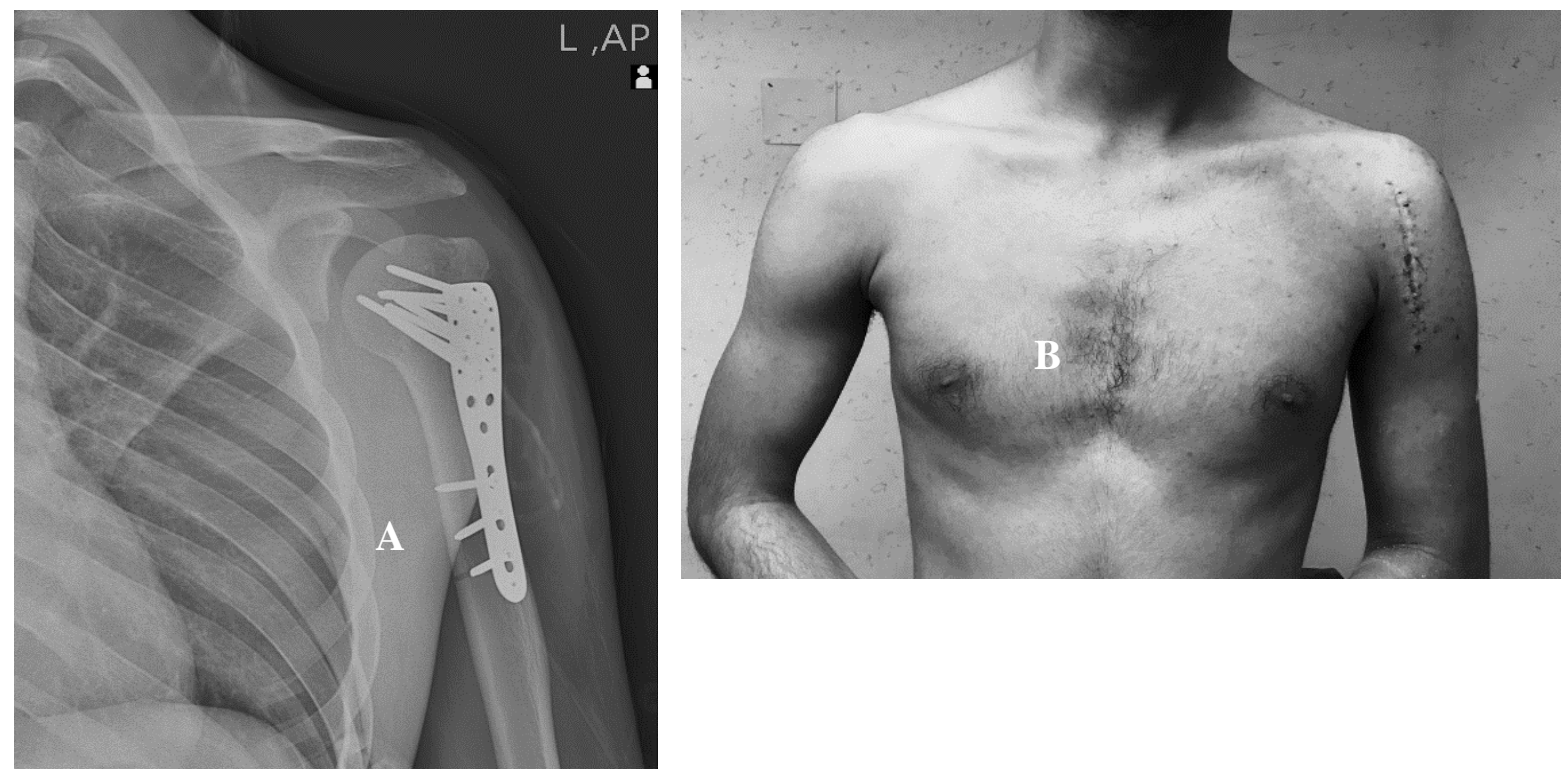

Figure 3. A. Radiograph at three-week follow up. Note mild inferior subluxation of humeral head and deltoid atrophy due to axillary nerve injury. B. Photograph of the patient showing deltoid atrophy
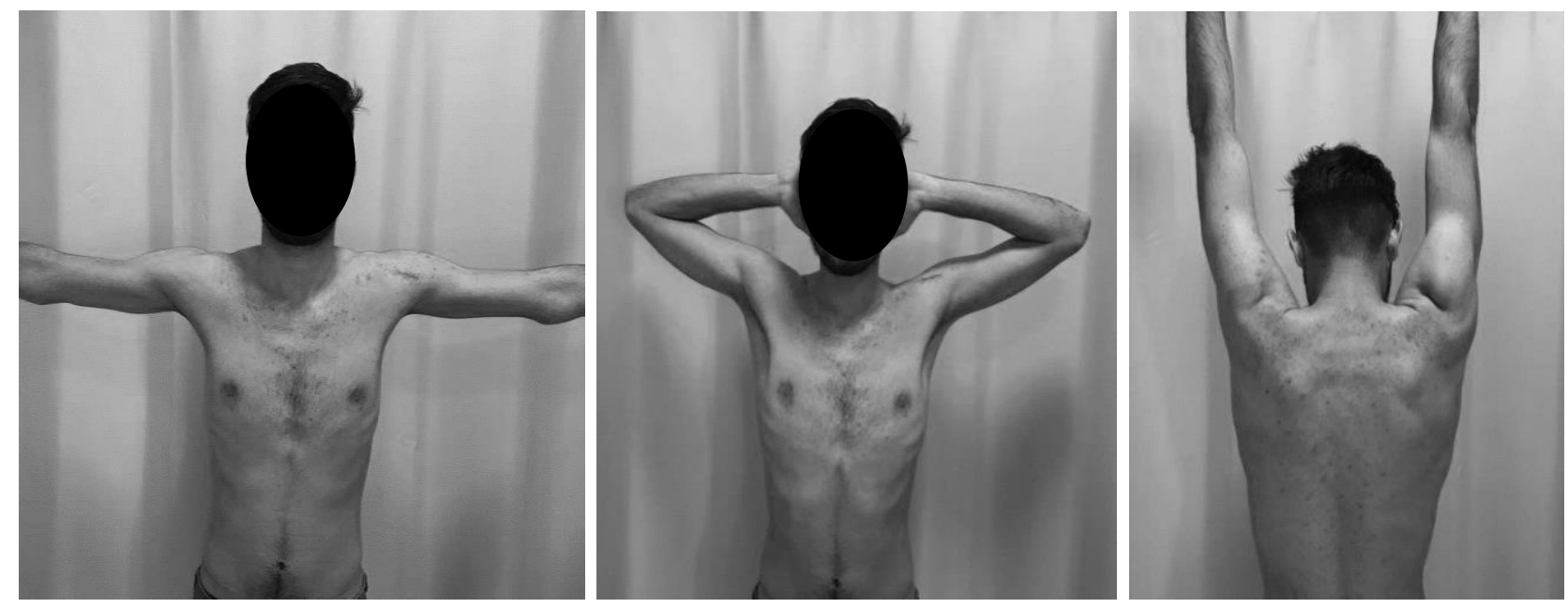

Figure 4. Photographs of the patient showing complete deltoid muscle recovery and symmetric range of motion of the shoulders 

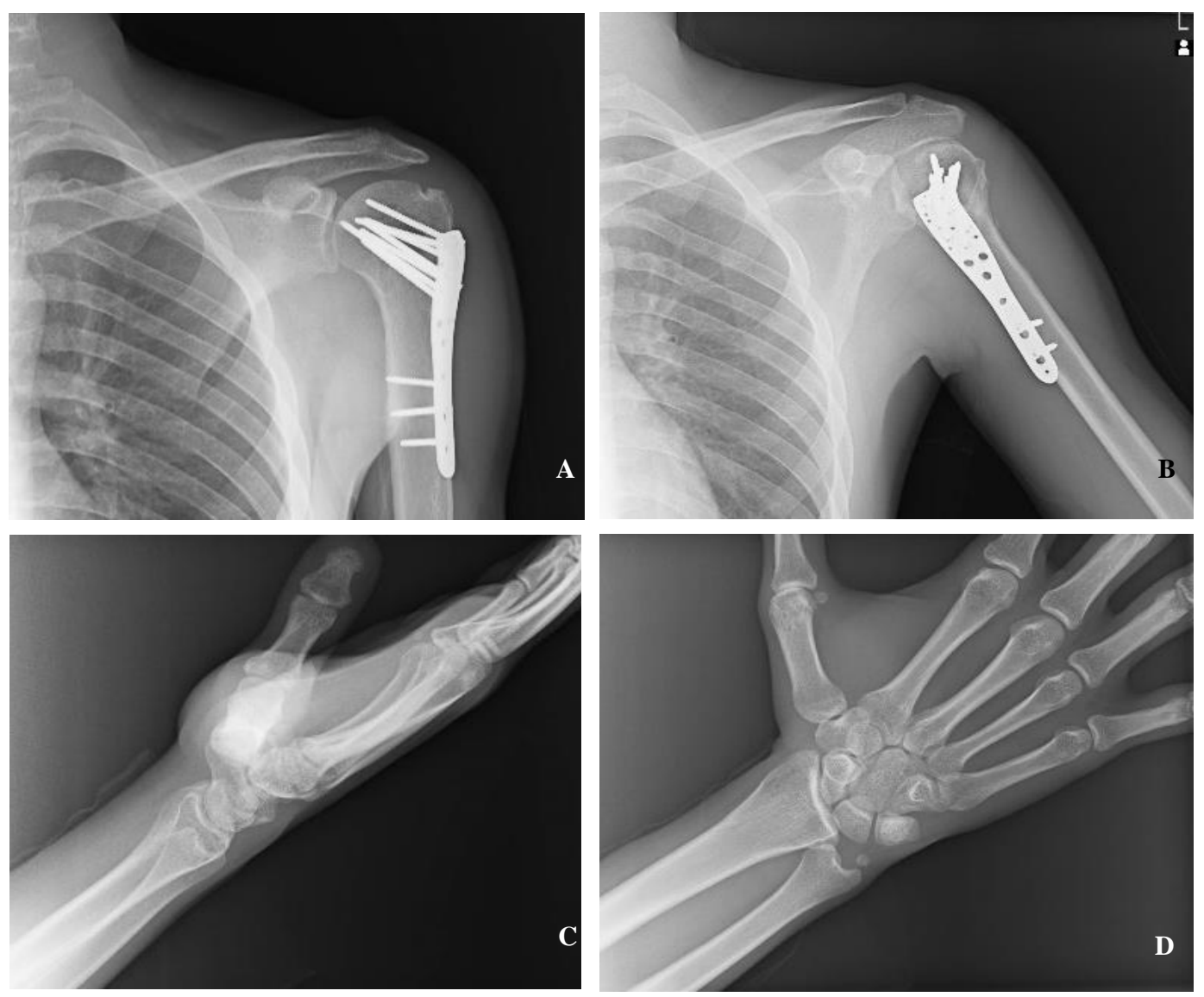

Figure 5. Radiographs of a follow-up 6 months after surgery showing complete union of proximal humeral and distal radius fracture. There is no subluxation of the humeral head due to complete recovery of the axillary nerve injury.

\section{Discussion}

AIN palsy due to proximal humeral fractures is very uncommon. There is only one similar case in the literature. Tanagho et al. reported the case of an 87year-old woman with a proximal humeral fracture and AIN palsy, both of them were treated conservatively. The patient completely recovered from AIN palsy after six months (4).

The lateral and medial cords of the brachial plexus form the median nerve (C5-T1). It does not provide motor or sensory innervation until it reaches the elbow (5). AIN mostly originates from 5 to 8 distal to the lateral epicondyle of the humerus (6). Along its course in the forearm, AIN innervates the FPL, pronator quadratus, and FDP to the index and middle finger (7).

The causes of AIN palsy can be divided into spontaneous and traumatic. Gantzer's muscle, brachial plexus neuritis, Volkmann's ischemic contracture, compression neuropathy, and enlarged bicipital bursa are related to non-traumatic causes. Traumatic (or secondary) causes are mostly due to traction, supracondylar or forearm fractures, penetrating injuries, direct trauma, and cast fixation $(4,7)$.

Compression neuropathy frequently occurs when pressure is applied to the forearm for a long time, open venipuncture in the antecubital fossa, fibrotic bands formed by intense weight lifting, or sometimes spontaneously with no obvious cause (8). In these patients, paralysis may develop several weeks or even months after the injury occurs. It seems that in our patient, AIN palsy could not be attributed to compression neuropathy because it happened after the accident and a near-complete recovery occurred without surgical intervention. Brachial plexus neuritis can also present itself clinically as a form of isolated AIN palsy $(9,10)$, but in our patient, this is improbable because nerve palsy happened immediately after the trauma.

Although the AIN is deep and relatively well protected, direct trauma to the forearm can be considered as a causative factor. The patient's history and examinations revealed no evidence of trauma or injury around the elbow.

Median nerve variations have been well-documented in the literature. It normally forms from two roots, whereas although formation from three, four, or five roots has been described as well. In addition, median nerve formation distal to the axilla has been found in 
an incidence of $3.5 \%$ to $40 \%$ of specimens (11). Sunderland has also been isolated AIN fibers from the proximal part of the median nerve at the level of brachial plexus (12). So, displaced bony fragments could cause the rupture, contusion, or dysfunction of these fibers in the arm.

According to a study done by Kleinrensink, traction injury of the median nerve and the medial cord may occur after falling with the elbow and wrist extended (13). Also, because of the limited mobility and small size of the AIN, it is more vulnerable to tension injury than the median nerve (14). In displaced supracondylar humerus fractures in children, the AIN is held firmly in the forearm by tethering structures such as ulnar collateral vessels, tough fibrous bands of the pronator teres (deep head), the Gantzer's muscle, and the proximal bony fragment act as a distracting element. Nerve injury usually happens immediately, and spontaneous recovery usually takes three weeks to four months $(8,15)$.

Because neurologic deficit occurred immediately after fracture, authors believe that either traction injury due to stretching of hand or nerve contusion due to bony fragments and median nerve variations might cause nerve palsy in this patient. In view of the fact that most nerve lesions after proximal humeral fracture are neuropraxia, spontaneous functional recovery should be expected in these patients and surgical intervention is not necessary. Although, baseline EMG seems to be rational for further comparison. Repeating EMG would have been advisable to monitor the recovery and to allow timely intervention if necessary.

\section{Conclusion}

AIN palsy is a very rare complication following proximal humeral fractures. Therefore, orthopedic surgeons should be aware of the possibility of this complication, and special care should be taken while examining patients with such injuries. A correct diagnosis contributes to optimal treatment. Surgical intervention is not necessary unless no signs of recovery are evident at the three-month follow-up.

\section{Acknowledgment}

The authors would like to thank the Rasoul Akram Hospital Clinical Research Development Center (RCRDC) for its technical and editorial assistance.

\section{Conflict of Interest}

Authors declared no conflict of interests.

\section{References}

1. Philipp N. Streubel JS-S, Steinmann P. Proximal humeral fractures. Rockwood and Green's
Fractures in Adults. 1. eighth ed: Lippincott Williams \& Wilkins; 2015. p. 1341-425.

2. Hems TE, Mahmood F. Injuries of the terminal branches of the infraclavicular brachial plexus: patterns of injury, management and outcome. J Bone Joint Surg Br. 2012;94(6):799-804. [DOI:10.1302/0301-620X.94B6.28286]

3. Visser CP, Coene LN, Brand R, Tavy DL. Nerve lesions in proximal humeral fractures. J Shoulder Elbow Surg. 2001;10(5):421-7. [DOI:10.1067/mse.2001.118002]

4. Tanagho A, Elgamal T, Ansara S. Anterior interosseous nerve palsy as a complication of proximal humerus fracture. Orthopedics. 2013;36(10):e1330-2. [DOI:10.3928/0147744720130920-29]

5. Mazurek MT, Shin AY. Upper extremity peripheral nerve anatomy: current concepts and applications. Clin Orthopaedics Relat Res. 2001(383):7-20. [DOI:10.1097/00003086200102000-00004]

6. Wertheimer A, Kiel J. Anatomy, Shoulder and Upper Limb, Forearm Anterior Interosseous Nerve. StatPearls. Treasure Island (FL): StatPearls Publishing. 2019.

7. Aljawder A, Faqi MK, Mohamed A, Alkhalifa F. Anterior interosseous nerve syndrome diagnosis and intraoperative findings: A case report. Int $\mathrm{J}$ Surg Case Rep. 2016;21:44-7. [DOI:10.1016/j.ijscr.2016.02.021]

8. Mirovsky Y, Hendel D, Halperin N. Anterior interosseous nerve palsy following closed fracture of the proximal ulna. A case report and review of the literature. Arch Orthop Trauma Surg. 1988;107(1):61-4. [DOI:10.1007/BF00463528]

9. Steed JT, Drexler K, Wooldridge AN, Ferguson M. Anterior interosseous nerve neuropraxia secondary to shoulder arthroscopy and open subpectoral long head biceps tenodesis. Case Rep Orthopedics. 2017;2017:7252953. [DOI:10.1155/2017/7252953]

10. Wong L, Dellon AL. Brachial neuritis presenting as anterior interosseous nerve compression-implications for diagnosis and treatment: a case report. J Hand Surg. 1997;22(3):536-9. [DOI:10.1016/S0363-5023(97)80025-1]

11. Natsis K, Paraskevas G, Tzika M. Five roots pattern of median nerve formation. Acta Medica (Hradec Kralove). 2016;59(1):26-8. [DOI:10.14712/18059694.2016.52]

12. Sunderland $S$. The innervation of the flexor digitorum profundus and lumbrical muscles. Anat Rec. 2005;93:317-21. [DOI:10.1002/ar.1090930402] 
13. Kleinrensink GJ. Influence of posture and motion on peripheral nerve tension: Anatomical, biomechanical and clinical aspects: Erasmus University Rotterdam; 1997.

14. Collins DN, Weber ER. Anterior interosseous nerve avulsion. Clin Orthopaedics Relat Res. 1983(181):175-8. [DOI:10.1097/00003086198312000-00028]

\section{How to Cite This Article:}

Sobhani Eraghi A, Hosseinzadeh N. Anterior Interosseous Nerve Palsy Following Proximal Humeral Fracture: A Case Report. J Adv Med Biomed Res. 2020; 28 (126) :17-22

\section{Download citation:}

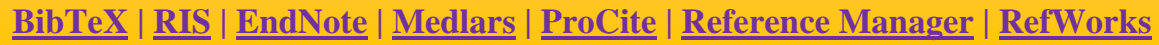

\section{Send citation to:}

Mendeley 2 Zotero (i) RefWorks RefWorks
15. Kumar V, Singh A. Fracture supracondylar humerus: a review. J Clin Diag Res. 2016;10(12):Re01-re6. [DOI:10.7860/JCDR/2016/21647.8942]

variation: absence of the radial artery. Anat Record. 1986;214(1):89-95. [DOI:10.1002/ar.1092140115] [PMID] 